\title{
Abstracts
}

\section{Joint Conference of BASEM and BASES}

\section{TOTAL HIP REPLACEMENT AND GOLF: IMPACT ON PARTICIPATION AND PERFORMANCE}

\section{J. Arbuthnot, M. McNicholas, H. Dashti, G. Stables}

There is little information that the orthopaedic surgeon can provide for patients concerned about the effect of a total hip arthroplasty (THA) operation on their ability to continue playing golf and at what level they can hope to play.

We present the results of a study into the effect of THA for osteoarthritis on the golfing habits and performance of 750 patients. We sent 750 patients a questionnaire, which enquired about their participation in golf before and after the operation. We received 698 replies, 66 of which were from golfers.

Harris hip scores are prospectively acquired before surgery and at regular intervals afterwards for all patients undergoing hip arthroplasty at our centre. Comparisons of hip scores for golfers were consistently higher than for non-golfers at all intervals.

There was no statistically significant difference in the number of games played, maximum shot distance, shot accuracy, handicap, or ability to walk around the course after the operation.

We conclude that THA does not have a detrimental effect on golf participation or performance.

\section{A RETROSPECTIVE STUDY OF THE DEMOGRAPHICS OF SPORT, EXERCISE, AND LEISURE RELATED INJURIES IN 1143 CHILDREN UNDER 17 PRESENTING TO AN EMERGENCY MEDICINE DEPARTMENT OVER A SIX MONTH PERIOD}

K.P. O'Rourke', S. Mun ${ }^{2}$, M. Browne ${ }^{3}$, J. Sheehan ${ }^{4}$ S. Cusack ${ }^{3}$, M. Molloy.' 'Department of Rheumatology, Cork University Hospital, Cork Ireland; ${ }^{2}$ Department of Paediatrics, Cork University Hospital; ${ }^{3}$ Department of Accident and Emergency, Cork University Hospital; ${ }^{4}$ Department of Epidemiology and Public Health, University College Cork, Cork

Aims: In Ireland, the demographics of sport related injury (SRI) in children has not adequately been described, as indicated by the paucity of publications in the medical literature, and the purpose of this study was to provide up-to-date data to correct this deficiency.

Methods: Data were collected on all children under 17 years of age with a SRI, presenting to the emergency medicine department of a major teaching hospital, over a six month period. The data, which included sport, age, sex, cause, type, site, time of injury, and management, were entered into a database.

Results: We analysed 23000 records, and identified 1143 SRls over a six month period, from 53 different sports. Our results indicate many statistical differences, some of which were previously unreported, including a high proportion of humerus $(p=0.03)$ and back $(p=0.01)$ SRls in girls, a higher proportion of falls in girls ( $p=$ $0.0001)$ and interindividual collisions in boys $(p=0.0001)$, low usage of protective gear $(6 \%$ of SRIs), infrequent advice on $\mathrm{RICE} /$ general injury (25\% of SRIs) and injury preventive measures $(<1 \%$ of SRIs), decreased analgesia prescription in children under age 5 , and rarity of topical analgesic prescription $<1 \%$ of analgesics prescribed).
Conclusions: The data provided may raise awareness of the different aspects of SRIs affecting children and may be important in formulating injury prevention strategies.

\section{A THREE MONTH HOME EXERCISE PROGRAMME IMPROVES PAIN AND FUNCTION IN A MILITARY POPULATION WITH RECALCITRANT ANTERIOR KNEE PAIN}

R.D. Phillip, A.K. Wills, J. Etherington. NDR Carter Defence Medical Rehabilitation Centre, Headley Court, Epsom, Surrey KT18 6JN, UK

Aim: To establish the effectiveness of a three month home exercise programme in the treatment of recalcitrant anterior knee pain (AKP) in a military population.

Method: Patients presenting to the Defence Medical Rehabilitation Centre (DMRC) between November 2001 and November 2002 with a diagnosis of AKP were allocated to a one week inpatient education and rehabilitation course. They were assessed for levels of pain intensity and effect using a visual analogue scale score, self reported disability using a Chesworth questionnaire, ${ }^{\prime}$ and function with a figure of 8 test. They were prescribed a progressive exercise regimen including eccentric loading, postural stability, and flexibility exercises, as well as cardiovascular fitness. They were reviewed after three months and the assessments were repeated.

Results: A total of 48 patients (41 men, seven women) were recruited with a mean (SD) age of $29.9(7.0)$ years and a duration of symptoms of $5.3(3.4)$ years. Bilateral symptoms were present in $38 \%$ of the patients. There was a significant improvement in all outcomes (table).

Conclusion: In service personnel with recalcitrant AKP, a three month home exercise programme results in a significant improvement in pain, self reported disability, and function.

1. Chesworth BM, Culham EG, Tata GE, et al. Validation of outcome measures in patients with patellofemoral syndrome. J Orthop Sports Phys Ther 1989:302-8.

\section{CONCUSSION IN SPORT: ARE RECOMMENDATIONS BEING FOLLOWED?}

H.C. Hart, W.A. Wallace, J.A. White, F.M. Coffey. Queen's Medical Centre, Nottingham NG7 2UH, UK

Aim: To determine if current concussion recommendations' for pitch side assistance and return to play practices are being followed.

Method: A retrospective postal questionnaire of persons who had presented as a sports casualty at accident and emergency, with signs and symptoms of concussion and/or a head, neck, chest, or thigh injury had a response rate of $58 \%(n=104 / 186)$.

Results: All respondents received a poor standard of pitch side first aid. Among the 26 concussed respondents, 11 were aware of guidelines used for safe return to play. However, seven admitted to evading injury detection, and 12 to ignoring guidelines or advice when returning to play (six to both and 13 to either). Although eight received a medical examination before returning to play, only seven did so in a stepwise fashion, which was significantly less than respondents without concussion injury $(n=63)(p<0.005)$. No concussed respondents had neurocognitive assessments.

Conclusion: In keeping with the finding of other studies, ${ }^{2}$ pitch side first aid needs to be improved to an acceptable standard. Objective

\begin{tabular}{|llllll|}
\hline \multicolumn{4}{l}{ Abstract 3} & \multicolumn{2}{l|}{ Changes in tested parameters (paired $t$ test) } \\
\hline & \multicolumn{2}{l}{ Paired differences } & \\
\cline { 2 - 5 } 3 months to 1 week & Mean & $95 \% \mathrm{Cl}$ & tStatistic & $\mathrm{p}$ Value \\
\hline Pain intensity $(\mathrm{n}=47)$ & -8.1042 & -0.21 to -16.00 & -2.064 & 0.045 \\
Pain effect $(\mathrm{n}=47)$ & -12.2083 & -3.05 to -21.37 & -2.682 & 0.010 \\
Chesworth questionnaire $(n=48)$ & 1.79 & 1.19 to 2.39 & 5.989 & 0.000 \\
Figure of 8 (seconds) $(\mathrm{n}=42)$ & -2.00 & -0.39 to -3.61 & 2.506 & 0.016 \\
\hline
\end{tabular}


Abstract 6 Effects of exercise on heart index, apoptotic ratio, and Bax and Bcl-2 gene expression

\begin{tabular}{lllllll}
\hline Group & $\mathrm{N}$ & Heart index (\%) & $\begin{array}{l}\text { Apoptotic ratio } \\
(\%)\end{array}$ & Bax gene & Bcl-2 gene & Bax/Bcl-2 ratio \\
\hline C & 7 & $0.27(0.01)$ & $0.76(0.562)$ & $0.22(0.070)$ & $0.21(0.094)$ & $1.239(0.621)$ \\
MT & 7 & $0.32(0.01)$ & $2.30(1.552)$ & $0.24(0.076)$ & $0.19(0.732)$ & $1.414(0.615)$ \\
HT & 7 & $0.30(0.02)$ & $7.21(2.776)$ & $0.29(0.037)$ & $0.17(0.106)$ & $2.317(1.844)$
\end{tabular}

Values are mean (SD)

C, Control; MT, middle intensity training; $\mathrm{HT}$, high intensity training

measures are justified in supervision of safe return to play after concussive injury.

1. Aubry M, Cantu R, Dvorak J, et al. Concussion in Sport Group. Summary and agreement statement of the First International Conference on Concussion in Sport, Vienna 2001. Recommendations for the improvement of safety and health of athletes who may suffer concussive injuries. Br J Sports Med 2002;36:6-10.

2. Cunningham $A$. An audit of first aid qualifications and knowledge among team officials in two English youth football leagues: a preliminary study. Br J Sports Med 2002;36:295-300.

\section{CARBOHYDRATE/ELECTROLYTE REPLACEMENT IN SOCCER PLAYERS}

S.M. Ostojic, V. Jorga. Sports Medicine Department, Institute for Medical Hygiene, Pasterova 2, Faculty of Medicine, University of Belgrade, Belgrade 11000, Serbia

The aim of this study was to examine the effects of a carbohydrate/electrolyte drink on specific soccer tests and performance. Twenty professional male soccer players volunteered to participate. They were allocated to one of two trials in which either carbohydrate/electrolyte drink ( $8 \%$ carbohydrates) or placebo was ingested during a 90 minute soccer match. The trials were matched for subjects' age, weight, height, maximal oxygen uptake, and playing positions. Immediately after the match, players completed six soccer specific skill tests. Subjects in the carbohydrate/electrolyte trial finished the specific dribble test faster those in the placebo trial (12.1 $(0.8)$ v $13.2(0.7)$ seconds; $p<0.05)$. Ratings of the precision test were higher in the carbohydrate/electrolyte trial than the placebo trial (16.8 (4.7) v 15.0 (4.1); $p<0.05)$, and the $20 \mathrm{~m}$ shuttle run test times were higher in the carbohydrate/electrolyte trial $(721.8$ (63.2) v 654.2 (45.5) seconds; $p<0.05$ ), but there were no differences in coordination test, balance test, and power test results between trials. The main finding of this study indicates that supplementation with carbohydrate/electrolyte solution improved soccer specific skill performance and recovery after a soccer match compared with ingestion of placebo.

\section{EFFECTS OF ENDURANCE TRAINING ON CARDIOMYOCYTE APOPTOSIS AND ITS RELATED GENE EXPRESSION}

J. Yuan', Y. Chang', R. Handy', J. Moody. 'China National Research Institute of Sports Science, Beijing 100061, P.R. China; ${ }^{2}$ School of Biological Science, University of Plymouth, Plymouth PL4 8AA, UK

This study aimed to investigate cardiomyocyte apoptosis and Bax and $\mathrm{Bcl}-2$ gene response to endurance exercise of different intensity. Sixty male Sprague-Dawley rats were randomised to a sedentary control group (C), middle intensity training group (MT), and high intensity training group $(\mathrm{HT})$. Rats in the latter two groups ran on treadmills at $30 \mathrm{~m} / \mathrm{min}$ and $38 \mathrm{~m} / \mathrm{min}$ respectively for 60 minutes a day for 12 weeks. Hearts were removed and weighed 24 hours after training. The apoptotic ratio was measured by flow cytometry. ${ }^{1,2}$ Bax and Bcl-2 gene expression were tested by QRT-PCR assay. ${ }^{3}$ The heart to body weight ratio (heart index) increased significantly in the $M T(p<0.01)$ and $\mathrm{HT}(\mathrm{p}<0.05)$ group compared with the $\mathrm{C}$ group. The apoptotic ratio increased in both the MT and HT group. Although no significant differences occurred between the MT and $\mathrm{C}$ groups, significant increases were observed in the HT group compared with the $C$ $(p<0.01)$ or MT $(p<0.05)$ group. Bax expression increased and Bcl-2 expression decreased in both training groups, but no significant difference between these groups was observed. Only the Bax/Bcl-2 ratio was significantly different in the HT group from the $C(p<0.05)$ and MT ( $<<0.05)$ group (table). Endurance training induced myocardiac hypertrophy and cardiomyocyte apoptosis at the same time. High volume training had more effect on cardiomyocyte apoptosis. The interaction of the Bax and Bcl-2 genes played a major role in regulating exercise induced cardiomyocyte apoptosis.

Note: This work was funded by State General Administration of Sports of P.R.China and carried out in the National Research Institute of Sports Science of P.R. China, Beijing.

1. Nicoletti I, Migliorati G, Pagliacci MC, et al. A rapid and simple method for measuring thymocyte apoptosis by propidium iodide staining and flow cytometry. J Immunol Methods 1991;139:271-9.

2. Yuan J, Chang Y. The observation on live cardiomyocyte apoptosis in athletic heart remodelling process. Chinese Journal of Sports Medicine $2001 ; 20: 348-51$.

3. Oltvai ZN, Milliman CL, Korsmeyer SJ. Bcl-2 heterodimerizes in vivo with a conserved homolog, Bax, that accelerates programmed cell death. Cell 1993;74:609-19.

\section{THE ERGOGENIC EFFECTS OF EURYCOMA LONGIFOLIA JACK: A PILOT STUDY}

S. Hamzah, A. Yusof. Department of Exercise Physiology, Sports Centre, University of Malaya, 50603 Kuala Lumpur, Malaysia

Eurycoma longifolia Jack (EL), which contains quassinoids such as eurycomalacton, eurycomanon, and eurycomanol, has been reported to have aphrodisiac properties and to increase testosterone levels in men.' Previous studies have established that the testosterone supplementation increases fat free mass, muscle strength, and muscle mass, which are important for physical function and athletic performance. ${ }^{2,3}$ Thus, the objective of this study was to investigate the effect of the increase in testosterone levels, obtained by administration of EL, on body composition and muscle strength and size in man. Fourteen healthy men performed an intense strength training programme with initial load of $60 \%$ RM (2 sets of 10 repetitions with 1 minute rest between, for 10 stations) on alternate days for five weeks. Simultaneously, seven men were randomly selected to consume $100 \mathrm{mg} /$ day EL water soluble extract, and seven men received placebo. The intensity of the exercise was increased by $10 \%$ RM/week. Body composition, arm circumference, one repetition maximum (1 RM), and surface electromyography (sEMG) activity were measured and recorded one day before and after the five weeks of supplementation and intervention. The lean body mass of the treatment group showed a significant increment, from $52.26(7.18) \mathrm{kg}$ to $54.39(7.43) \mathrm{kg}(\mathrm{p}=0.012)$, but no significant changes in fat free mass were observed in the placebo group. Percentage body fat was significantly decreased in the treatment and placebo group, from $31.30(5.48) \%$ to $28.44(6.43) \%$ $(p=0.01)$ and from $22.83(2.43) \%$ to $21.33(2.35) \%(p=0.001)$ respectively. The 1RM test showed a significant increase from 73.71 $(16.63)$ to $78.71(17.0) \mathrm{kg}(p=0.006)$ in the treatment group and from $77.29(8.9)$ to $79.43(8.8) \mathrm{kg}(\mathrm{p}=0.011)$ in the placebo group. The increase in strength in the treatment group was larger than in the placebo group $(6.78 \%$ and $2.77 \%$ respectively). The mean frequency of $s E M G$ on the biceps in the treatment and placebo groups decreased significantly, from $121.77(40.0)$ to $90.47(64.6) \mu \mathrm{V}(\mathrm{p}=$ $0.012)$ and from $127.95(30.9)$ to $98.8(50.1) \mu \mathrm{V}(p=0.036)$ respectively. The treatment produced $2.92 \%$ greater reduction in electrical activity of the muscle measured at the end of the experiment compared with placebo. The mean arm circumference of the treatment group increased significantly by $1.8 \mathrm{~cm}$ after the supplementation, from $30.87(1.88)$ to $32.67(1.96) \mathrm{cm}(p=0.011)$, but there was no significant increase in the placebo group. The results suggest that water soluble extract of Eurycoma longifolia Jack increased fat free mass, reduced body fat, and increased muscle strength and size, and 
thus may have an ergogenic effect. Further investigations are warranted.

1. Ismail MTM. Proceedings paper: Asian Congress of Sexology. 2002.

2. Bhasin S, Storer TW, Berman N, et al. The effects of supraphysiologic doses of testosterone on muscle size and strength in men. N Engl J Med 1996;335: 1-7.

3. Brodsky IG, Balagopal P, Nair KS. Effects of testosterone replacement on muscle mass and muscle protein synthesis in hypogonadal men: a Clinical Research Center Study. J Clin Endocrinol Metab 1996;81:3469-75

\section{DO CHILDREN BETWEEN THE AGES OF 11 AND 14 IN PRIVATE EDUCATION DO MORE EXERCISE THAN THOSE IN STATE EDUCATION?}

M. Desborough, C. Fisher, C. Goes, A. Hill, M. Kaye, N. McDermott, R. Ramphul, M. Toby. University of Sheffield Medical School, Royal Hallamshire Hospital, Glossop Road, Sheffield S10 5UY, UK

Aims: To discover whether children in private education do more exercise than those in state education during the pubertal growth spurt and to offer some explanation for this.

Methods: A total of 299 pupils aged 11-14 years from five schools took part. Hours of exercise taken by pupils $(a)$ in school PE lessons, (b) in organised school activities, and (c) outside school were recorded in a questionnaire. Pupils were asked if their parents exercised and asked to offer reasons why they didn't do as much exercise as they intended. Lastly, lists of sporting facilities available at schools were obtained.

Results: The mean (SD) of total exercise taken by state school and private school pupils was 4.29 (4.39) hours and 5.39 (3.86) hours respectively. Using an independent $t$ test at the $95 \%$ significance level, $t=-2.28103$ and $p=0.02325$.

Conclusion: The results suggest that pupils attending private schools do significantly more exercise than those attending state schools. If these results have national significance, state school pupils will accumulate less bone density' and will consequently be at greater risk of suffering from osteoporosis later in their lives.

1. MacKelvie KJ, Khan KM, Mc Kay HA. Is there a critical period for bone response to weight-bearing exercise in children and adolescents? A systematic review. Br J Sports Med 2002;36:250-7.

\section{EFFECT OF FOUR WEEKS OF REHABILITATION FOR CHRONIC ANKLE INSTABILITY ON POSTURAL CONTROL AND SELF REPORTED DISABILITY}

J. Hertel, S.A. Hale, L.C. Olmsted. Department of Kinesiology, Pennsylvania State University, University Park, PA, USA

Our aim was to investigate the effects of a four week rehabilitation programme on postural control and self reported disability in young adults who suffered from chronic ankle instability (CAl). Twelve individuals with unilateral CAI and 17 with no history of sprain to either ankle participated. Postural control, in both eyes open and eyes closed conditions, was quantified with measures of centre of pressure excursion velocity (COPV) during trials of quiet standing in single leg stance. Disability was quantified with the foot and ankle disability index (FADI), a survey that assesses activities of daily living as well as sport specific tasks. Measures were taken at baseline and four weeks later. The CAl group completed four weeks of supervised ankle rehabilitation while the control group had no intervention. Analysis of variance revealed significant group by side interactions for the FADI scores, but not for the COPV measures. CAl subjects reported substantial disability on their involved limbs compared with their uninvolved limbs at baseline, and significant improvement in function on the involved limbs after rehabilitation. Subjective self reports appear to be more sensitive than postural control measures in detecting functional deficits associated with CAI

\section{ALTERED MYOCARDIAL ELECTROPHYSIOLOGY AFTER PROLONGED ILLICIT ANABOLIC ANDROGENIC STEROID USE}

F.M. Grace, N. Sculthorpe, A.D. Gething, M.T. Graham, J.S. Baker, B. Davies. Centre For Ergogenic Drug Research, Department of Health and Exercise Science, University of Glamorgan, Wales, UK

Aim: To examine myocardial electrical stability using signal averaging electrocardiography (SAECG) to asses the presence of late ventricular potentials (LPS) in long term anabolic androgenic steroid (AAS) users, and to compare these findings with an age matched control group.

Method: LPS are measured, using surface electrodes, as high frequency signals and are located at the terminal portion of the QRS complex. Such areas of slow inhomogeneous conduction are thought to decrease myocardial electrical stability and provide a re-entry mechanism for malignant ventricular tachycardias.' After ethical approval from Bro Taf health authority, written informed consent and family medical history was gained from 20 subjects. The subjects were split into two groups: (a) long term (22 (3) years; range 18-30) steroid users $(\mathrm{n}=10)$, which included three previous international competitors and two current competitors, including one national champion and one senior national champion; (b) sedentary controls (n $=10)$. Subjects were matched for age and $V_{2}$ Max. No subjects reported any history of syncope, cardiovascular disease, or bouts of tachyarrhythmias. Both groups underwent SAECG analysis at rest and after an acute bout of exercise to volitional exhaustion. LPS were analysed using a $40 \mathrm{~Hz}$ filter and averaged over 200 beats. Differences between groups were assessed by two way analysis of variance. Incidence was calculated as a percentage of the sample with abnormal SAECGs as previously defined.

Results: At rest and after an acute bout of exercise, there was no difference in the mean values for any of the LP criteria. However, there was a higher incidence of abnormal LPS in AAS users than in controls, both at rest $(30 \% v 10 \%)$ and after an acute bout of exercise $120 \% v$ $0 \%$ ). The incidence of abnormal SAECG in the control group is in agreement with the previous literature. ${ }^{2}$

Conclusion: Long term AAS use may cause increased electrophysiological instability in certain people, both at rest and after exercise. This may place AAS users at an increased risk of malignant tachyarrhythmias. Although it is an intriguing possibility that, in some people, long term AAS use may push physiological adaptation to a more pathological process, it is speculative at this stage because of the lack of echocardiographic evaluation. However, further study is justified.

1. Breithardt G, Cain M, El-Sherif N, et al. American College of Cardiology position statement. J Am Coll Cardiol 1991;17:9991006.

2. Monroe K, Kimoto K, Inove T, et al. Jpn Circ J 1995;59:225-47.

Abstract 11 Subject characteristics and concentrations of male sex hormones and $C$ reactive protein at time of testing

\begin{tabular}{|c|c|c|c|c|c|}
\hline & AAS Using-on $(n=8)$ & AAS Using-off $(n=7)$ & $\begin{array}{l}\text { Bodybuilder controls } \\
(n=8)\end{array}$ & $\begin{array}{l}\text { Sedentary controls } \\
(n=9)\end{array}$ & Normal range \\
\hline Group ID & SU & SA & $\mathrm{BC}$ & SC & \\
\hline Length of AAS use (years) & $19(2.3)$ & $20(2.5)$ & $\mathrm{N} / \mathrm{A}$ & $\mathrm{N} / \mathrm{A}$ & \\
\hline Body mass index $\left(\mathrm{kg} / \mathrm{m}^{2}\right)$ & $34.4(2.7)^{* *}$ & $34.7(3.7)^{* *}$ & $28.3(2.0)$ & $27.1(2.9)$ & \\
\hline Testosterone (nmol/l) & $57.4(21)^{*}$ & $19.6(4.9)$ & $16.3(5.7)$ & $14.3(3.6)$ & $8-30$ \\
\hline SHBG (nmol/l) & $4.3(2)^{* *}$ & $12.5(7.5) \dagger$ & $23.7(8.9)$ & $26(15.2)$ & $15-100$ \\
\hline $\mathrm{CRP}(\mathrm{mg} / \mathrm{l})$ & $3.6(1.4)$ & $1.3(0.7)$ & $0.9(0.5)$ & $1.2(0.9)$ & $(<6.0)$ \\
\hline
\end{tabular}

Values are mean $(S D)$

${ }^{*} p<0.05,{ }^{*} p<0.01$ compared with controls.

tSignificantly lower than BC and SC but not SU.

N/A, Not applicable; AAS, anabolic androgenic steroid; SHBG, sex hormone binding globulin; CRP, C reactive protein 
Abstract 12 Subject characteristics and concentrations of male sex hormones and biochemical markers of thyroid function at time of testing

\begin{tabular}{lllll}
\hline & $\begin{array}{l}\text { AAS Using-on } \\
(\mathbf{n}=8)\end{array}$ & $\begin{array}{l}\text { AAS Using-off } \\
(\mathrm{n}=7)\end{array}$ & $\begin{array}{l}\text { Bodybuilder controls } \\
(\mathrm{n}=8)\end{array}$ & $\begin{array}{l}\text { Sedentary controls } \\
(\mathrm{n}=9)\end{array}$ \\
\hline Group ID & SU & SA & BC & SC \\
Length of AAS use (years) & $19(2.3)$ & $20(2.5)$ & $\mathrm{N} / \mathrm{A}$ & $\mathrm{N} / \mathrm{A}$ \\
Body mass index (kg/m²) & $34.4(2.7)^{* *}$ & $34.7(3.7)^{* *}$ & $28.3(2.0)$ & $27.1(2.9)$ \\
Testosterone (nmol/l) & $57.4(21)^{*}$ & $19.6(4.9)$ & $16.3(5.7)$ & $14.3(3.6)$ \\
SHBG (nmol/l) & $4.3(2)^{* *}$ & $12.5(7.5) \dagger$ & $23.7(8.9)$ & $26(15.2)$ \\
TSH (mU/l) & $2.1(0.8)$ & $3.4(1.0)$ & $2.3(1.2)$ & $3.7(1.1)$ \\
$\mathrm{T}_{4}(\mathrm{nmol} / \mathrm{l})$ & $83(14)$ & $76(19)$ & $74(17)$ & $88(20)$ \\
\hline
\end{tabular}

Values are mean (SD)

${ }^{*} p<0.05,{ }^{* *} p<0.01$ compared with controls.

†Significantly lower $(\mathrm{p}<0.05)$ than $\mathrm{BC}$ and $\mathrm{SC}$ but not SU.

N/A, Not applicable; AAS, anabolic androgenic steroid; SHBG, sex hormone binding globulin; $T S H$, thyrotrophin; $T_{4}$, thyroxine.

\section{ELEVATED LEVELS OF C REACTIVE PROTEIN IN THE ILLICIT ANABOLIC ANDROGENIC STEROID USER}

F.M. Grace, B. Davies. Centre for Ergogenic Drug Research, Department of Health and Exercise Science, University of Glamorgan, Wales, UK

Aim: To investigate the effects of anabolic androgenic steroid (AAS) use on a biochemical marker for inflammatory disease, $C$ reactive protein.

Method: After ethical approval from the local health authority, AAS using participants were recruited to the study. Subjects were divided into four distinct groups: AAS users $(n=7)$ who were still using at the time of testing (A); AAS users $(n=8)$ who had been abstinent for more than three months (mean (SD) 4.6 (3.1) months) (B); bodybuilding controls $(n=8)$ who did not use any pharmacological ergogenic aids $(C)$; sedentary male controls $(n=10)(D)$.

Venous blood was sampled for testosterone, sex hormone binding globulin, and $C$ reactive protein using standardised procedures and appropriate techniques.

Results: Significant differences in male sex hormones (table) provided indirect confirmation of AAS use. Results also indicated significantly higher $(p<0.05) C$ reactive protein levels in the AAS using group than the bodybuilding and sedentary controls.

Conclusion: $C$ reactive protein, a marker of systemic inflammation, appears to be elevated through the illicit use of AAS. The significance of the magnitude of elevation warrants further investigation. This study adds to the body of literature providing contraindications to the nontherapeutic use of AAS.

\section{LACK OF IMPAIRMENT OF THYROIDAL FUNCTION AFTER LONG TERM ILLICIT USE OF ANABOLIC ANDROGENIC STEROIDS}

F.M. Grace, B. Davies. Centre for Ergogenic Drug Research, Department of Health and Exercise Science, University of Glamorgan, Wales, UK

Aim: To investigate the effects of long term anabolic androgenic (AAS) use on indices of thyroid function and compare with control groups who did not use any non-nutritional ergogenic aids.

Method: Subjects were divided into four distinct groups: AAS users $(n=7)$ who were still using at time of testing $(A)$; AAS users $(n=8)$ who had been abstinent for more than three months (mean (SD) 4.6 (3.1) months) (B); bodybuilding controls $(\mathrm{n}=8)$ who did not use any pharmacological ergogenic aids $(C)$; sedentary male controls $(n=10)$ (D). The AAS using control group had abstained from AAS use for a minimum of 12 weeks before examination. Venous blood samples were sampled from the antecubital vein after an overnight fast and 30 minutes supine rest using the standard venepuncture method.

Results: Body mass index was significantly higher $(p<0.01)$ in both groups of AAS users compared with controls. Although there were significant differences between groups for testosterone and sex hormone binding globulin, there were no significant differences between groups for either thyroid stimulating hormone or thyroxine (table).

Conclusion: Although long term AAS use is associated with a variety of potentially pathological conditions, the present study indicates a lack of effect of such illicit AAS use on thyroid function.

\section{EFFECTIVENESS OF A MULTIDISCIPLINARY CARDIAC REHABILITATION PROGRAMME ON THE PSYCHOLOGICAL WELLBEING OF MYOCARDIAL INFARCTION SURVIVORS}

E.M. Board, C.F.M. Arrighi, J. Thatcher. Sport and Exercise Sciences, School of Social Sciences and Law, University of Teesside, Middlesbrough TSI 3BA, UK

It is well documented that myocardial infarction (MI) survivors commonly suffer psychological disturbances, such as anxiety and depression, the consequences of which for some patients are transient but for others are persistent and disabling. The National Service Framework for Coronary Heart Disease (Department of Health, 2000) highlights the need to address the psychological needs of cardiac patients. Therefore the aim of this study was to examine the short term and long term effectiveness of a multidisciplinary cardiac rehabilitation programme on the anxiety and depression levels of MI survivors. After their $\mathrm{Ml}$, patients were invited to attend a six week cardiac rehabilitation programme, which included twice weekly exercise sessions (each one hour duration) and educational discussions covering topics such as cardiac health and medications, lifestyle, nutrition, stress management, and relaxation. Thirty three patients (29 male, four female; mean age 60.3 (7.8) years) volunteered to participate in the study. They completed the hospital anxiety and depression scale (HADS) ${ }^{1}$ at the start of the cardiac rehabilitation programme, at the end of the programme (short term effectiveness), and six months after the programme (long term effectiveness). It was found that $15 \%$ and $18 \%$ of patients exhibited substantial anxiety and depression respectively (HADS score greater than 11; table). Short term anxiety scores had decreased after the programme, but long term (six months after the programme) they had increased. Repeated measures analysis of variance revealed no significant differences in the anxiety scores over the short term and long term periods $(p>0.05)$. Depression scores showed similar, but significant $(p<0.05)$, trends with a short term reduction immediately after the programme and an increase at six months. To conclude, as the six month scores for both anxiety and depression increased, the study shows the need for long term monitoring of psychological wellbeing in cardiac patients beyond six months.

Abstract 13 Mean anxiety and depression scores before and after rehabilitation programme

\begin{tabular}{llll}
\hline & Before & After & Six months after \\
\hline Anxiety & $4.36(3.31)$ & $3.73(3.32)$ & $4.09(2.84)$ \\
Depression & $4.18(2.84)$ & $2.00(1.89)^{*}$ & $2.35(2.91)^{*}$ \\
\hline
\end{tabular}

Values are mean (SD).

* Significant difference from baseline (pre-programme) figures.

1. Zigmond AS, Snaith RP. The Hospital Anxiety and Depression Scale. Acta Psychiatr Scand 1983;67:361-70. 
014 IMMUNE FUNCTION IN RELATION TO PSYCHOLOGICAL STRESS AND PHYSICAL ACTIVITY

A.D. Flouris, J. Aird, G. Inglis, P. Klentrou. Faculty of Applied Health Sciences, Brock University, St Catharines, Ontario L2S3A I, Canada

The purpose of this study was to determine the effects of salivary cortisol $(\mathrm{s} C \mathrm{z})$ on salivary immunoglobulin $\mathrm{A}(\mathrm{s} \lg \mathrm{A})$ and frequency of upper tract respiratory infections in relation to psychological stress. Fifty (50) university students (27 men, 23 women) who had not received a flu vaccination for the past 12 months volunteered. They were assessed for slgA, slgA/albumin ratio, and $s \mathrm{Cz}$. Each subject completed the aerobics center longitudinal study physical activity questionnaire for estimation of weekly energy expenditure, and an 11 week health and sickness log for daily recording of symptoms of sickness. Measurements were performed in September (T1), a relatively low stress period, and November (T2), two weeks before the term final examinations. Analysis of variance indicated no significant $(p>0.05)$ differences between $\mathrm{T} 1$ and $\mathrm{T} 2$ in slgA concentration (210.36 (155.91) v 220.93 (157.39)), slgA/Albumin ratio (2.84 (0.72) v $2.84(0.79))$, and $s \mathrm{Cz}(6.6(3.56)$ v $6.84(4.18))$. slgA and $\mathrm{s} \mathrm{C} z$ were not related to weekly energy expenditure $(p>0.05)$. Students were below "optimal" levels for recommended physical activity levels. At both $\mathrm{T} 1$ and $\mathrm{T} 2$, slgA concentration was significantly lower $(p<0.05)$ and $\mathrm{s} C z$ concentration was higher $(p<0.05)$ than previously reported, indicating that subjects were overly stressed since the beginning of the year, which possibly resulted in imunosuppression.

\section{ELITE PERFORMANCE IN RELATION TO SPECIFIC CORTICAL STIMULI ACROSS DIVERSE SPORTING DISCIPLINES}

A.D. Flouris', G.S. Metsios. ${ }^{2}$ 'Faculty of Applied Health Sciences, Brock University, St Catharines, Ontario L2S3A1, Canada; ${ }^{2}$ School of Sports, Performing Arts and Leisure, University of Wolverhampton, Walsall WS13BD, UK

Recent scientific findings suggest that listening to the first movement of Mozart's Sonata for Two Pianos (K 448) causes significant improvements in spatial-temporal reasoning. This study investigated the effect of this precise neural stimulus on specific performance indices of elite athletes. A repeated measures, randomised block design required 26 elite male soccer players (12-16 years of age) and 24 elite male cricketers (14-17 years) to perform both spatial-temporal organisation speed and skill drills. Each drill was performed twice on two separate days, which included a 10 minute relaxation period before testing. Mozart's sonata was randomly implemented on headphones during one of the two sessions. During the remaining session, subjects were exposed to a silent recording. Analysis of variance indicated that performance in the skill test was significantly enhanced in both soccer $(\mathrm{p}<0.001)$ (stimuli $=41.76$ (17.15); non-stimuli $=33.38$ $(15.07))$ and cricket $(p<0.05)$ (stimuli $=10.10(2.54)$; non-stimuli $=$ 9.07 (2.54)) after the music stimuli session. Conversely, the stimuli produced no significant $(p>0.05)$ enhancement in speed for either soccer $($ stimuli $=4.90(0.48)$; non-stimuli $=5.01(0.24))$ or cricket (stimuli $=5.77(0.46)$; non-stimuli $=6.02(0.58))$. The results suggest that spatial-temporal stimuli can significantly enhance skill performance of elite athletes in soccer and cricket. Further research is required to evaluate the "Mozart effect" across other sport disciplines.

\section{RISK FACTOR PROFILES OF CORONARY HEART DISEASE IN PERI-ADOLESCENT YOUTH IN CANADA AND GREECE}

A.D. Flouris', C. Bouziotas ${ }^{2}$, B.E. Faught', Y. Koutedakis, ${ }^{3}$ S. Dobbin' 'Faculty of Applied Health Sciences, Brock University, StCatharines, Ontario, Canada; ${ }^{2}$ School of Health Sciences, University of Wolverhampton, Wolverhampton, UK; ${ }^{3}$ Department of Physical Education and Sports, University of Thessaly, Trikala, Greece

This study assessed the coronary heart disease risk factor profile of 12 year old children living in Canada and Greece. A sample of 396 youths ( 89 boys and 109 girls from each country) were evaluated for percentage body fat (\%BF), blood pressure (BP), total cholesterol (TC), maximum oxygen uptake $\left(\mathrm{VO}_{2} \mathrm{MAX}\right)$, and participation in physical activity (PPA). In Canadian and Greek boys, there were noticeable differences between the reported prevalence for clinical obesity (>25\%BF; 0.23 (0.09) v $0.28(0.09)$ ), high TC levels $(>4.0 \mathrm{mmol} ; 0.26(0.09)$ v $0.82(0.09))$, and low $\mathrm{VO}_{2} \operatorname{MAX}(<40 \mathrm{ml} / \mathrm{kg} / \mathrm{min} ; 0.46(0.1) \vee 0.44$ (0.1)) respectively. This was also evident in Canadian and Greek girls for clinical obesity (>30\%; $0.28(0.08) \vee 0.21(0.08))$, high TC levels $(0.28(0.08) \vee 0.69(0.09))$, and low $\mathrm{VO}_{2} \operatorname{MAX}(<35 \mathrm{ml} / \mathrm{kg} / \mathrm{min} ; 0.81$ (0.07) v $0.39(0.09)$ respectively. Analysis of variance detected significantly higher values for diastolic and mean arterial BP, TC, and lower $\mathrm{VO}_{2}$ MAX in Greek boys $(p<0.05)$. Furthermore, significantly higher values for weight, body mass index, diastolic and mean arterial $\mathrm{BP}, \% \mathrm{BF}$, and TC as well as lower $\mathrm{VO}_{2} \mathrm{MAX}$ and PPA were found for Greek girls ( $<<0.05)$. In assessing common risk factor trends, stepwise regression analyses showed $\mathrm{VO}_{2} \mathrm{MAX}$ and PPA predicting clinical obesity and low $\mathrm{VO}_{2} \mathrm{MAX}$ levels respectively in both countries. Finally, $\mathrm{TC}$ was predicted by $\mathrm{VO}_{2} \mathrm{MAX}$ and \% $\mathrm{BF}$ in boys and girls, respectively.

\section{IMPACT OF COLLAGEN FRAGMENTS ON THE TYPE I COLLAGEN BIOSYNTHESIS OF CHONDROCYTES}

S. Oesser, J. Seifert. Surgical Research, Department of General and Thoracic Surgery, University of Kiel, Michaelisstrasse 5, D-24105 Kiel, Germany

Aim: The integrity of articular cartilage is dependent on the maintenance of the extracellular matrix (ECM), which is controlled by chondrocytes.' In the regulation of ECM biosynthesis, a variety of substances have been found to influence chondrocyte metabolism. ${ }^{2}$ The effect of degraded collagen on the formation of type II collagen by mature bovine chondrocytes was investigated in a cell culture model.

Methods: The culture medium was supplemented with collagen hydrolysate, and biosynthesis of type II collagen by chondrocytes was compared with control cells treated with native type I and type II collagen and a collagen-free protein hydrolysate. ${ }^{3}$ The quantification of type II collagen by ELISA was confirmed by immunocytochemical detection and by the incorporation of $\left[{ }^{14} \mathrm{C}\right]$ proline into the $\mathrm{ECM}$. Chondrocytes in the control group were maintained in the basal medium for 11 days.

Results: The presence of extracellular collagen hydrolysate led to a dose dependent increase in type II collagen secretion. Native collagens as well as a collagen-free protein hydrolysate failed to stimulate the production of type II.

Conclusion: These results clearly indicate a stimulatory effect of degraded collagen on the type II collagen biosynthesis of chondrocytes and suggest a possible feedback mechanism for the regulation of collagen furnover in cartilage tissue.

1. Huber M, Tratting S, Lintner F. Anatomy, biochemistry, and physiology of articular cartilage. Invest Radiol 2000;35:573-80.

2. Rosier RN, O'Keefe RJ. Autocrine regulation of articular cartilage. Instr Course Lect 1998;47:469-75.

3. Oesser S, Seifert J. Stimulation of type II collagen biosynthesis and secretion in bovine chondrocytes cultured with degraded collagen. Cell Tissue Res 2003;311:393-9.

\section{IS DURATION OF LOW BACK PAIN ASSOCIATED WITH INCREASED SCINTIGRAPHIC UPTAKE IN THOSE INVESTIGATED FOR SPONDYLOLYSIS?}

P.S. Webb, P.L. Gregory. Queen's Medical Centre, Nottingham, UK

Spondylolysis may result from repeated stress of sporting activity on the posterior element of the lumbar spine. The condition may be suspected in a patient with extension related low back pain. Initial investigation of spondylolysis is by single photon emission computed tomography (SPECT). SPECT reveals bone responding to stress with increased bone metabolism. This study compares characteristics of patients with positive and negative SPECT results.

Patients having had SPECT scans at QMC, Nottingham between 1995 and 2001 were studied ( $n=379$; 193 male, 186 female): 201 patients had negative and 178 had positive SPECT results.

SPECT positivity was associated with a period of shorter than 12 months of pain before the SPECT scan $\left(\chi^{2}, p=0.0036\right)$. Sporting involvement $\left(\chi^{2}, \mathrm{p}=<0.001\right)$ and being male $\left(\chi^{2}, \mathrm{p}=<0.001\right.$; adjusted odds ratio $=3.41$ (95\% confidence interval 2.20 to 5.28$)$ ) were also independently associated with positivity.

Investigating by SPECT within a time frame of 12 months from pain onset is more likely to yield positive results. The explanation may be that increased bone metabolism tends to normalise after such periods, or that pain persisting for longer than one year is less likely to be due to spondylolysis. 


\section{EFFECT OF SOFT TISSUE THERAPY ON HIP JOINT RANGE OF MOTION, SYMPTOMS, AND EGGBEATER KICK PERFORMANCE IN WATER POLO PLAYERS}

\section{A Mosler. Australian Institute of Sport}

The purpose of this study was to examine whether a specific course of soft tissue intervention would have an effect on hip joint range of movement, symptoms, and eggbeater kick performance in water polo players. Sixteen elite male water polo players aged 16-19 years participated in the randomised crossover study. The ranges of hip joint passive and active internal and external rotation, and active abduction were measured. A questionnaire including visual analogue scales was used to determine current symptoms. In water, performance tests consisted of a maximal jump height test and an eggbeater endurance to fatigue test. The intervention consisted of eight 45 minute sessions of soft tissue therapy over a period of four weeks. The results show a significant difference between the control and experimental groups in passive internal and external rotation and total passive range of movement $(p=0.05)$. A trend towards greater increases in active range of rotation in the experimental group was noted, but this was not significant because of the increased range also occurring in the control group. The intervention had no effect on the abduction range of movement. There was a significant negative effect of the intervention on visual analogue scale scores, and the clinical significance of this statistical finding is discussed. Odds ratios showed that the intervention was effective in increasing the likelihood of improvement in both jump height and eggbeater endurance. There was no correlation between changes in any of the variables of range of movement or symptoms and the performance tests. The improved performance could be a result of several mechanisms, and these are discussed. The implications of the study for clinical management of hip syndromes and for further research are also discussed.

\section{DIFFERENCE IN RANGE OF SHOULDER ROTATION IN WRIST SPIN AND FINGER SPIN CRICKET BOWLERS}

R. Chauhan, P.L. Gregory. Center for Sports Medicine, Division of Orthopaedic \& Accident Surgery, Queen's Medical Center, University Hospital, Nottingham, UK

Objective: To assess the range of shoulder rotation in dominant and non-dominant shoulders of wrist and finger spin bowlers in relation to increase in age and years of that type of bowling.

Methods: A total of 60 spin bowlers aged 10-19 were recruited from young cricketers training at centres of excellence from five counties in England in February 2003. There were 36 wrist and 24 finger spin bowlers. In both the groups, using a goniometer, passive range of internal and external rotation of the glenohumeral joint was measured in the bowling and non-bowling shoulders with the upper arm at $90^{\circ}$ of abduction. Players were supine, and the scapulothoracic joint was stabilised, ensuring that true glenohumeral motion was measured without significant contribution from the acromioclavicular, scapulothoracic, or sternoclavicular joints.

Results: The mean internal rotation in the non-dominant shoulder was significantly greater than in the dominant shoulder, in both wrist and finger spin bowlers. Also, with increased age, in both types of bowler, internal rotation in the non-dominant shoulder was significantly greater than in the dominant shoulder. Similar findings were also seen with an increase in years of doing that particular kind of bowling.

Conclusion: Significant loss in range of internal rotation is seen at the shoulder joint in the dominant shoulders compared with non-dominant shoulders of wrist and finger spin bowlers and also with an increase in age and years of that type of bowling. This should be considered in stretching exercises, rehabilitation protocols, and surgical repair of shoulder injury of spin bowlers.

\section{KNOWLEDGE OF BANNED SUBSTANCES IN SPORTS}

H. Weithers', P.L. Gregory', J. White', A. Lorde. ${ }^{2}$ 'Centre For Sports Medicine, Queens Medical Centre, University of Nottingham, UK; ${ }^{2}$ Barbados Sports Medicine Association

Aim: To evaluate the current state of knowledge of doctors, pharmacists, and medical and pharmacy students in recognising banned drugs in Barbados.

Method: A self administered questionnaire testing knowledge of four banned over the counter (OTC) drugs and four banned prescription drugs was piloted and used for the study. The pharmacy and medical students completed the questionnaires in class. The pharmacists and doctors represented a convenience sample of those registered to practice. Questionnaires were administered in their work place.

Results: Fewer than half of all the cohorts correctly recognised all the banned substances. In the OTC subset, 22 pharmacists $(N=45)$, 13 doctors $(N=45), 13$ medical students $(N=37)$, and five pharmacy students $\left(N^{\prime}=37\right)$ were able to correctly identify all the banned preparations. The pharmacists were significantly better at identifying the banned OTC drugs than the doctors ( $p=0.035)$ and pharmacy students $(p=0.011)$. In the prescription drug subset, four pharmacists, five doctors, eight medical students, and no pharmacy students correctly identified all four banned drugs.

Conclusion: There is lack of adequate knowledge in these cohorts on banned preparations. As athletes will seek advice on drugs in sport from these professionals and future professionals, measures should be taken to address this deficiency.

\section{MANAGEMENT OF ANKLE SPRAINS: A RANDOMISED CONTROLLED TRIAL OF THE TREATMENT OF INVERSION INJURIES USING AN ELASTIC SUPPORT BANDAGE OR AN AIRCAST ANKLE BRACE}

S.H. Boyce, M.A. Quigley, S. Campbell

Objective: To determine the functional outcome of the ankle joint after a moderate or severe inversion injury, comparing standard treatment with an elastic support bandage against an Aircast ankle brace.

Design: Prospective, randomised controlled trial.

Setting: Two centre study, accident \& emergency departments.

Method: Fifty patients presenting consecutively were randomised to two equal groups and allocated an elastic support bandage or an Aircast ankle brace. All patients were given a standardised advice sheet referring to rest, ice, compression, and elevation. Review arrangements were made for $48-72$ hours, 10 days, and one month.

Primary outcome measure: Ankle joint function was assessed at 10 days and one month using the modified Karlsson scoring method (maximum score 90)

Secondary outcome measure: The difference in ankle girth (swelling) and pain score at 10 days.

Results: Seventeen patients completed the study in the elastic support bandage group (six defaulted and two were excluded). Eighteen patients completed the study in the Aircast ankle brace group (six defaulted, one was excluded). There were no significant differences between the two groups in terms of age (mean 33.5 years and 32.6 years for the elastic bandage and Aircast groups respectively), sex, dominant leg, left or right ankle injured, previous injury, or time to presentation (median number of hours three and four for the elastic bandage and Aircast groups respectively). Differences in ankle girth (median $20 \mathrm{~mm}$ ) and pain scores (median 6) were similar in the two groups at presentation. Using Student's $t$ test, the Karlsson score was significantly higher in the Aircast group than the elastic bandage group at day 10 (mean $50 \vee 35, p=0.028,95 \%$ confidence interval (Cl) 1.7 to 27.7 ) and at one month (mean 68 v 55, $p=0.029,95 \%$ $\mathrm{Cl} 1.4$ to 24.8 ). There was no difference between the groups in the secondary outcome measures (swelling, $p=0.09$; pain, $p=0.07$ ). Using hierarchical multiple regression analysis to correct for possible baseline confounding factors, the Aircast group was significantly associated with higher Karlsson scores at day $10(p=0.009)$ and one month $(p=0.024)$

Conclusion: The use of an Aircast ankle brace to treat lateral ligament ankle sprains produces a significant improvement in ankle joint function at both 10 days and one month compared with standard management with an elastic support bandage.

\section{IS MAGNETIC RESONANCE IMAGING OF VALUE IN THE INVESTIGATION OF GROIN PAIN? A STUDY OF 127 FOOTBALLERS}

F.W. Smith

To evaluate the value of magnetic resonance imaging (MRI) of the pelvis for footballers complaining of groin pain, the MRI scans of 127 footballers aged 11-30 years who had been referred because of either groin or hip pain were reviewed. The footballing ability of the players covered all levels from schoolboy through to international.

In 63 cases (50\%), no abnormality was found. There were 19 cases of osteitis pubis, nine of stress fracture, five of adductive muscle tear, six with hamstring problems, 10 with inflammation of the small muscles of the hip, and four of iliopsoas tendonitis. The remaining 11 
cases had various other findings, including two cases of benign bone tumour (one osteochondroma and one case of fibrous dysplasia).

Of the 63 patients with no abnormality on the MRI scan, 10 subsequently had surgery for conjoint tendonitis. Although the MRI scan showed no significant abnormality in players who subsequently had surgery for conjoint tendonitis, MRI is useful for finding other causes of groin and hip pain. It is particularly sensitive in revealing unsuspected pathology such as stress fractures and benign bone tumours.

\section{EFFECTS OF CREATINE SUPPLEMENTATION ON THE BRAIN MONITORED BY PROTON MAGNETIC RESONANCE SPECTROSCOPY}

I.D. Wilkinson, N. Mitchell, S. Breivik, P. Greenwood, P.D. Griffiths, E.M. Winter, E.J.R. van Beek. Academic Unit of Radiology, University of Sheffield and The Centre for Sports and Exercise Science, Sheffield Hallam University, Sheffield, UK

Oral creatine supplementation can enhance exercise performance. This study investigated the effects of oral creatine supplementation on the brain using magnetic resonance (MR) spectroscopy.

With ethics committee approval, 18 young sportsmen provided written informed consent and participated. In a double blind trial, 12 subjects consumed $20 \mathrm{~g} /$ day creatine monohydrate dissolved in a masking solution for five days, and the remaining six a placebo similarly disguised. Immediately before and after the trial, participants were scanned on a clinical MR system (Eclipse; Philips Medical). Proton spectra were obtained from frontal cerebral white matter at short and long echo times (20 and 135 milliseconds), and results were expressed as areas under the choline, creatine, and $\mathrm{N}$-acetyl resonances and their ratios. After confirmation of underlying assumptions (normality, etc), spectra were compared across groups using a mixed design factorial analysis of variance (significance set at $\mathrm{p}<0.05)$.
There were no interactions between groups for creatine, choline, $\mathrm{N}$-acetyl, or related ratios, indicating that creatine supplementation and placebo groups did not differ significantly in any of the measures ( $p>0.05)$.

The results suggest that creatine supplementation by the dosing regimen used does not significantly alter the "MR visible" creatine pool in frontal cerebral white matter in young, active sportsmen.

\section{ASSESSMENT OF IN VIVO THREE DIMENSIONAL KNEE MOVEMENT BY MRI ACQUISITION AND IMAGE REGISTRATION}

I.D. Wilkinson, A.D. McCarthy, S. Wood, D. Chan, D.C. Barber, G. Darwent, D.R. Bickerstaff, D.R. Hose. Academic Radiology, Medical Physics and 'Sheffield Centre of Sports Medicine, University of Sheffield, UK

An image registration based method to calculate in vivo knee joint motion from magnetic resonance imaging (MRI) data has been developed as part of a European multicentre project aimed at developing a generic medical simulation environment (SimBio EU IST 10378). Its ultimate purpose is to permit validation of finite element computer simulations of knee joint motion, aimed at developing subject specific meniscal implant design.

A MR compatible rig was designed and built for imaging knee motion under load. All imaging was performed on a standard clinical MRI system (Eclipse; Philips Medical). High resolution static T2* weighted volumetric knee data and quasi-dynamic $\mathrm{Tl}$ weighted cine images of knee movement were acquired and segmented manually. A rigid transformation method was developed to register the segmented volume on to the sparse dynamic segments, and a non-linear least squares minimisation method was used to decompose the resultant matrix into its Euler rotation components.

Calculated joint angles of the tibia relative to the femur demonstrate the knee's screw home mechanism.

Our findings indicate that the combination of individual MRI acquisitions, image segmentation, and rigid body registration can be used to study and assess three dimensional joint motion. 